\title{
Evaluating reanalysis and satellite-based precipitation at regional scale: A case study in southern Mexico
}

\author{
Mirce Ivón MORALES-VELÁZQUEZ ${ }^{1}$, Graciela del Socorro HERRERA ${ }^{2 *}$, Javier APARICIO $^{3}$, \\ Arezoo RAFIEEINASAB ${ }^{4}$ and René LOBATO-SÁNCHEZ ${ }^{5}$ \\ ${ }^{1}$ Programa de Maestría y Doctorado en Ingeniería, Facultad de Ingeniería, Universidad Nacional Autónoma de \\ México, edificio S "Bernardo Quintana Arrioja”, piso 1, Ciudad Universitaria, 04510 Ciudad de México, México. \\ ${ }^{2}$ Departamento de Recursos Naturales, Instituto de Geofisica, Universidad Nacional Autónoma de México, Circuito \\ de la Investigación Cientifica s/n, Ciudad Universitaria, 04510 Ciudad de México, México. \\ ${ }^{3}$ Comisión Nacional del Agua, Av. Insurgentes Sur 2416, Copilco el Bajo, 04340 Ciudad de México, México. \\ ${ }^{4}$ Research Applications Laboratory, National Center for Atmospheric Research, 3090 Center Green Drive, Boulder, \\ CO 80301, USA. \\ ${ }^{5}$ Instituto Mexicano de Tecnología del Agua, Paseo Cuauhnáhuac 8532, Col. Progreso, 62550 Jiutepec, Morelos, México. \\ *Corresponding author; e-mail: ghz@igeofisica.unam.mx
}

Received: November 1, 2019; accepted: June 2, 2020

\begin{abstract}
RESUMEN
Los datos precisos de precipitación son esenciales para cualquier estudio hidrometeorológico, en particular para la calibración y simulación de modelos hidrológicos. En este artículo evaluamos la precipitación de dos productos diferentes de reanálisis (ERA5 y GLDAS) y dos productos de precipitación basados en satélites (TRMM 3B42 y CHIRPS) sobre las cuencas del río La Sierra en el sur de México, a escalas de tiempo regionales y diarias, de 2008 a 2010. Comparamos los datos de precipitación en malla con las mediciones de precipitación in situ en cada estación de medición, así como la precipitación media espacial (PME) sobre las cuencas en el área de estudio para los diferentes productos. El coeficiente de correlación de Pearson, la raíz del error cuadrático medio y las métricas de sesgo multiplicativo sugieren que CHIRPS y ERA5 son los productos de precipitación de mayor calidad en el área de estudio. CHIRPS tiene un mejor desempeño en la comparación de malla a punto, estimando mejor los eventos de precipitación de $10-50 \mathrm{~mm}$, por encima de $100 \mathrm{~mm}$, y para todos los valores sin umbral. ERA5 tiene un mejor desempeño para precipitaciones de 0-10 y 50-100 mm. Estos dos conjuntos de datos también tienen un mejor rendimiento en la representación de la variabilidad espacial de la lluvia de acuerdo con la precipitación media anual y el análisis de PME, mostrando valores de los estadísticos cercanos entre sí.
\end{abstract}

\begin{abstract}
Accurate precipitation data is essential for any hydrometeorological study, particularly for calibration and simulation of hydrological models. In this paper, we evaluate the precipitation of two different reanalysis products (the ERA5 and GLDAS), and two satellite-based precipitation products (TRMM 3B42 and CHIRPS) over the La Sierra river basins in Southern Mexico, on regional and daily time scales, from 2008 to 2010. We compare the collocated gridded precipitation data against in-situ precipitation measurements in each gauge station, as well as the mean areal precipitation (MAP) over the catchments in the study area for the different products. The Pearson correlation coefficient, the root mean square error, and the multiplicative bias metrics suggest that CHIRPS and ERA5 are the highest quality precipitation products over the study area. CHIRPS performs better on the grid to point comparison, estimating better precipitation events from 10-50 mm, above $100 \mathrm{~mm}$, and for all the values without threshold. ERA5 does better for precipitation from 0-10 and $50-100 \mathrm{~mm}$. These two datasets also have better performance on representing the spatial rainfall variability according to the mean annual precipitation and MAP analysis, showing statistical values close to each other.
\end{abstract}

Keywords: precipitation assessment, reanalysis, satellite. 


\section{Introduction}

"If you can't measure it, you can't improve it" (Peter Drucker). This statement is valid in every aspect of science and business. In hydrology in particular, measurements are not always sufficiently available or accurate. Nonetheless, precise precipitation measurements and estimates are essential for resource quantification studies, hydrological and meteorological modeling, decision making, and for disaster prevention in extreme weather events (Larson and Peck, 1974; Habib et al., 2001).

Ground measurements are often scarce or have low temporal resolution. Additionally, ground measurement devices fail or are destroyed during extreme weather events, such as tropical cyclones, resulting in lack of data during these high-impact events. Another problem is that these devices take point measurements whose values need to be interpolated and/or extrapolated to provide estimates in areas with no in-situ measurements (Ciach, 2003; Upton and Rahimi, 2003; Ly et al., 2013). Radar-derived rainfall provides spatial estimates at high spatial and temporal resolutions with larger areal coverage if they are properly calibrated and maintained. However, radar usage is limited in mountainous regions (Borga, 2002; Villarini and Krajewski, 2010; Nanding et al., 2015; Rico-Ramírez et al., 2015). This leads to the convenience of complementary data sources, such as satellite-based global climate information and numerical weather prediction (NWP) products, which are not limited by topography or device fragility.

The main advantages of satellite-derived rainfall estimates are their high spatial resolution, coverage, and near real-time availability (Paredes-Trejo et al., 2016). These products can be divided into three groups (Coning, 2013): (1) Single satellite source data sets such as the GOES precipitation index (GPI; Arkin et al., 1994) and The Hamburg Ocean Atmosphere Parameters and Fluxes from Satellite data record (HOAPS; Andersson et al., 2010); (2) satellite combination data sets such as the Climate Precipitation Center (CPC) Morphing Technique (CMORPH; Joyce et al., 2004) and the Global Precipitation Measurement Mission (GMP; Hou et al., 2014); and (3) a combination of data sets with gauge data (these data sets are the products of input data from more than one sensor type, including satellites and rain gauges) like PERSIANN (Hsu et al., 1997),
Global Precipitation Climatology Project (GPCP; Adler et al., 2003), TRMM Multi-Satellite Precipitation Analysis (TMPA) Rainfall Estimate Product 3B42 (TRMM 3B42; Huffman et al., 2007), and Climate Hazards Group InfraRed Precipitation with Station data (CHIRPS; Funk et al., 2015). A broader list of available datasets can be found at http://www.isac. cnr.it/ ipwg/data/datasets.html.

Alternatively, reanalyses generated by different national or regional agencies provide multivariate, spatially complete, and coherent records of the global atmospheric circulation. Some examples are the Global Land Data Assimilation System (GLDAS; Rodell et al., 2004), North American Land Data Assimilation System (NLDAS; Mitchell et al. 2004; Xia et al., 2012), Modern-Era Retrospective Analysis for Research and Applications (MERRA; Rienecker et al., 2011), and ERA5 (Hersbach et al., 2018). These reanalysis datasets are produced via data assimilation, a process that relies on observations and model-based forecasts to improve model output (Parker, 2016).

The successful performance of any hydrological application is largely determined by the quality of precipitation input data. Thus, when using these precipitation products, it is essential to first evaluate their quality, as has been done recently in different regions (Nkiaka et al., 2017; Albuquerque et al., 2018; Ghodichore et al., 2018; Wang et al., 2019). Some studies in Mexico have been done to assess the quality of satellite and NWP products such as Real-Rangel et al. (2017), who evaluated GLDAS-1, GLDAS-2, MERRA-2 precipitation estimates over Mexico against five climatological stations finding that MERRA-2 was the best fit followed by GLDAS-2 and GLDAS-1.

Some efforts have been done to estimate rainfall in Mexico using satellite platforms. One of the first products was developed by adapting Adler and Negri's technique (1988) to develop the estimator known as EPPrePMex hydroestimator (Sánchez-Sesma and Sosa-Chiñas, 2007). This was the first real-time rainfall estimator calibrated for the Mexican territory. It showed an overestimation tendency, but the estimation was better for convective storms.

Yucel et al. (2009) used the NOAA/NESDIS hydroestimator to evaluate convective rainfall for northwest Mexico with observed surface rainfall data collected during the North American Monsoon 
Experiment for the years 2002 and 2003. Results, though encouraging, showed overestimation in the daily accumulations for both topography and no topography considerations, despite that rain gauges and the GOES imagery depicted the diurnal variation very well. Mendoza (2019) used the precipitation rate estimated directly from the GOES-16 and showed overestimation for most of the country. The method of precipitation rate estimation is the one proposed by Kuligowsky (2002), whose calibration depends on a low orbiting satellite SSM/I, and it can be adjusted nearly in real-time via linear regression. The GOES16 algorithm for precipitation rate estimation also requires local adjustments because, as mentioned before, it depends on the SSM/I.

There are many studies on the quality of satellite-derived precipitation, like Perdigón-Morales et al. (2017), who analyzed duration and intensity of precipitation estimates from CHIRPS over the midsummer drought (MSD) in Mexico. Results indicated that CHIRPS provided a more detailed spatial representation than had ever been obtained before. Bruster-Flores et al. (2019) assessed the performance of the CMORPH product with corrected bias (CMORPH-CRT) in 14 sites in Mexico covering different climates and based on weather automatic stations. The evaluation was performed on two temporal scales, $30 \mathrm{~min}$ and daily based on two approaches: categorical metrics and statistical indicators. Results indicated that the CMORPHCRT product overestimates the number of precipitation events in most cases showing weak to moderate correlations. Mayor et al. (2017) evaluated the precipitation product of the Integrated Multi-Satellite Retrievals for Global Precipitation Measurement (IMERG) over Mexico on hourly, daily and seasonal time scales for cumulative precipitation using 99 automatic meteorological stations and continuous and categorical statistics. The results indicate that hourly precipitation performance is quite poor with correlation values of 0.18 , while a better performance was found at daily and seasonal time scales.

The present study evaluates the precipitation from two different reanalysis products (ERA5 and GLDAS), and two satellite-based precipitation products (TRMM 3B42 and CHIRPS) at storm-scale (1-10 km) over the La Sierra river basins located in southern Mexico, characterized by a high flood frequency occurrence and frequently hit by extreme meteorological events. The Sabancuy radar is available in the area; however, despite the advantages previously mentioned, two factors limit its use in the study area: it does not cover the area entirely, and the region contains a mountainous part.

The main difference between the previous studies in Mexico and this one is that previous analyses were developed at coarser scales considering selected stations over Mexican regions, or in the case of Mendoza (2019) over the Nayarit state, while the objective of the present study is to develop the analysis at a watershed scale. The use of these kinds of datasets is vital in areas where in-situ observations are scarce for calibration of hydrological models, which are implemented at the watershed scale. Additionally, the present study covers both, reanalysis and satellite-based precipitation products, and the evaluation is carried out based on statistical indicators and not categorical metrics on a daily time scale. This study will contribute to the evaluation of different precipitation datasets at a scale that is normally used to drive hydrological models, offering a contribution to the hydrometeorological community and hydrological model users.

This paper is organized as follows: section 2 describes the study area, sources of data and methodology used. Results and discussion are provided in section 3 and section 4 provides conclusion and future recommendation.

\section{Data and methods}

\subsection{Study area}

The area of interest is shown in Figure 1 where the red rectangle represents the domain of analysis, which encompasses La Sierra river basin and its contribution from Teapa river, from now on called La Sierra river basins, located between the states of Tabasco and Chiapas, Mexico. The domain area is $21528 \mathrm{~km}^{2}$ while the basins of interest are $4573 \mathrm{~km}^{2}$ in total. La Sierra river is one of the three main rivers contributing to the Grijalva river flow, one of the largest rivers in Mexico which crosses the city of Villahermosa, Tabasco and drains into the Gulf of Mexico (GOM). This zone is characterized by a high flood frequency occurrence and it is frequently hit by extreme meteorological events. 


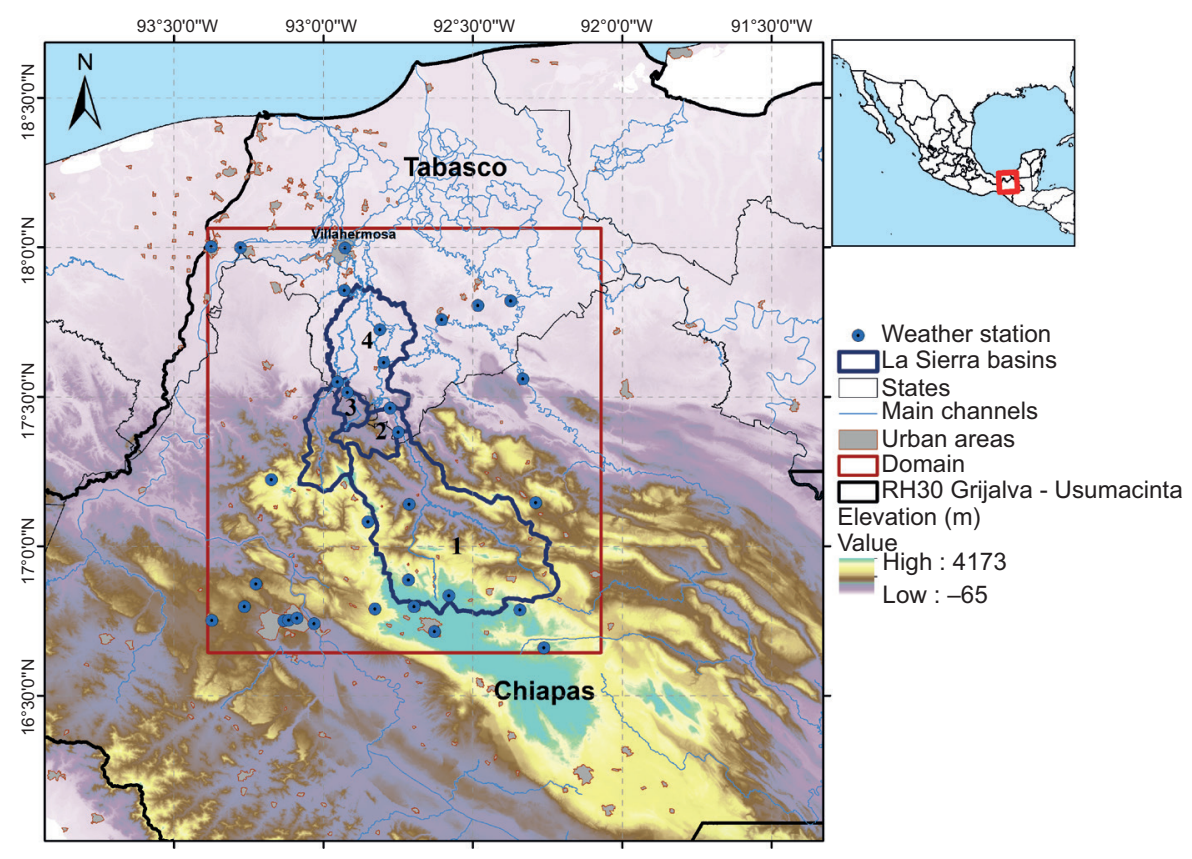

Fig. 1. La Sierra river basins location and spatial distribution of weather stations over the study area.

The upper part of the study area, within the state of Chiapas, is shaped by mountainous regions that comprise the Sierra de Chiapas, with elevations around 4000 masl. These mountains intercept the moisture carried by winds from the GOM, which favors a humid climate with rains all year-round. In contrast, plains dominate the lower part of the state of Tabasco, as part of the coastal plain of the southern GOM with elevations of a few dozen masl (CONAGUA, 2013, 2015) (Fig. 1).

Precipitation is analyzed from 2008 to 2010 . This period encompasses important meteorological events such as tropical cyclones Karl and Matthew, along with the presence of the Intertropical Convergence Zone in the higher Grijalva River basin during 40 days in 2010, with an accumulated precipitation of $1572 \mathrm{~mm}$ in such period (Arreguín-Cortés et al., 2014). Such intense precipitation event caused flood danger in the city of Villahermosa and important floods in the floodplain.

The number labels shown in Figure 1 are intended to identify each of the basins within the study area and facilitate the interpretation of results in the following sections. Each basin corresponds to the catchment area of the hydrometric stations shown in Table I.
Note that there are zones with no rain gauges, which could affect the results when estimating mean areal precipitation (gauge interpolated).

Table I. Basins ID and area.

\begin{tabular}{lll}
\hline Basin name & Basin ID & Area $\left(\mathrm{km}^{2}\right)$ \\
\hline Oxolotán & 1 & 2792.58 \\
Tapijulapa & 2 & 280.37 \\
Puyacatengo & 3 & 127.89 \\
Pueblo Nuevo & 4 & 1372.28 \\
\hline
\end{tabular}

\subsection{Data sources}

This subsection describes the data sources used and their general characteristics. Global free sources of information, like reanalysis or satellite data, are used in Mexico to derive adequate hydroclimatic variables needed in the simulation of hydrological processes and water balance studies (Real-Rangel et al., 2017). This kind of data is important in Mexico and other developing countries where in-situ observations are scarce. 


\subsubsection{In-situ observations}

The National Weather Service of Mexico (SMN, by its Spanish acronym) oversees the gathering, concentrating, reviewing and disseminating of climate information using the CLICOM (computerized climate) computer system developed by the World Meteorological Organization (WMO) in the mid1980s. This database contains data from more than 5000 stations distributed throughout the country. It offers daily data, reported every $24 \mathrm{~h}$ at 8:00 LT for the precipitation, evaporation and maximum and minimum temperature for each location (https:// smn.conagua.gob.mx/). Regarding precipitation, the measurements are done by means of tipping bucket gauges and the SMN performs a first quality control over the data identifying missing values, reviewed, corrected and doubtful data.

The in-situ precipitation data used in this study is taken from this database. The information can be downloaded from the SMN portal (https://smn. conagua.gob.mx/es/climatologia/informacion-climatologica/informacion-estadistica-climatologica) for short periods of time, while requests of longer periods need to be solicited directly to the SMN. After an exploratory data analysis, it was concluded that for the analysis period, 32 climatological stations within the study area were acceptable based on continuity and statistical dispersion of the data. Their locations are shown in Figure 1.

It is important to note that since the SMN is the main source of land climatological data in Mexico, a number of the datasets used in this study might have incorporated some of this data in the bias correction of their precipitation estimation, as it will be mentioned in the following sections.

\subsubsection{Reanalysis precipitation datasets}

\subsubsection{GLDAS}

GLDAS is a global, high-resolution, offline (uncoupled to the atmosphere) terrestrial modeling system that incorporates satellite and ground-based observations, using land surface modeling and data assimilation techniques, to produce optimal fields of land surface states and fluxes in near-real time (Rodell et al., 2004).

GLDAS offers land surface model simulations of Noah (Ek et al., 2003), Common Land Model (CLM; Dai et al., 2003), Variable Infiltration Capacity
Model (VIC; Liang et al., 1994) and Mosaic (Koster and Suárez, 1996) available in a 3-h temporal resolution, $1^{\circ}$ and $0.25^{\circ}$ spatial resolution from 1979 to present. For the present study, the $0.25^{\circ}$ resolution V2.1 data was used on the analysis period of 2008 to 2010 , which is available at https://disc.gsfc.nasa. gov/datasets/GLDAS_NOAH025_3H_V2.1/summary?keywords $=$ GLDAS_VIC10 $3 \overline{\mathrm{H}}$.

Previous studies have analyzed the performance of this dataset, such as Real-Rangel et al. (2017), who evaluated precipitation and streamflow variables on GLDAS v. 1 and 2 and MERRA-2 over Mexico, assessing absolute values and its variability. The results on precipitation values considering five climatological stations, showed that MERRA-2 was the best fit with ground observations closely followed by GLDAS-2, whereas GLDAS-1 values were not acceptable. All the products showed poorer performance in reproducing precipitation variability than absolute magnitude. In particular, the results suggest that mid to long-term variability are reproduced better than short-term fluctuations (one month).

\subsubsection{ERA5}

ERA5 is the latest atmosphere, ocean waves and land reanalysis of the meteorological reanalysis project European Centre for Medium-Range Weather Forecasts (ECMWF). It replaces the ERA-Interim reanalysis that was started in 2006 (spanning 1979 onwards) and encompasses the period covered by ERA-40. ERA5 is based on 4D-Var data assimilation using Cycle 41r2 of the ECMWF's Integrated Forecasting System (IFS) (Hersbach et al., 2018). This dataset provides hourly output for its variables and three-hourly output for its uncertainty estimations. It covers the Earth on a $30 \mathrm{~km}$ grid resolution and uses 137 levels from surface up to a height of $80 \mathrm{~km}$. The ERA5 hourly data on single levels from 2008 to 2010 are used in this study, which is available at Copernicus Climate Change Service Climate Data Store (CDS) https://cds.climate.copernicus.eu/cdsapp\#!/home.

\subsubsection{Satellite datasets}

\subsubsection{TRMM $3 B 42$}

The Tropical Rainfall Measuring Mission (TRMM) is a joint mission between NASA and the Japan Aerospace Exploration Agency (JAXA) to study rainfall 
for weather and climate research. It was launched in November 1997 and ended collecting data on April $15,2015$.

The TRMM 3B42 product v. 7 combines precipitation of four passive microwave (PMW) sensors, namely TRMM Microwave Imager (TMI); Special Sensor Microwave/Imager (SSM/I) F13, F14, and F15; Advanced Microwave Scanning Radiometer-EOS (AMSR-E); and Advanced Microwave Sounding Unit-B (AMSU-B). These data are merged to produce a combined satellite rainfall estimate every $3 \mathrm{~h}$, which is then summed to a monthly scale to be recalibrated using monthly precipitation gauge analysis. These two merged products, satellite rainfall estimates $(\mathrm{S})$ and gauge data $(\mathrm{G})$, provide the final three-hourly $0.25^{\circ}$ $\times 0.25^{\circ}$ quasi-global $\left(50^{\circ} \mathrm{N}-\mathrm{S}\right)$ gridded SG-rainfall database (Huffman et al., 2007; MacRitchie, 2017). The data used in this study was obtained from the Greenbelt, MD, Goddard Earth Sciences Data and Information Services Center (GES DISC) (https://doi. org/10.5067/TRMM/TMPA/3H/7).

Some studies have been done in Mexico using this dataset. Aurea et al. (2016) evaluated the standardized precipitation index (SPI) during the period of 1998 to 2013 using the TRMM 3B42 product and compared it against the rain gauge-based SPI getting low to medium correlations but still being able to capture the most relevant droughts at national scale. Gochis et al. (2009) assessed the performance of five remotely sensed precipitation products in their ability to represent the statistical characteristics of the North American Monsoon (NAM) over northwest Mexico and southwest US during 2004. Additionally, a comparison between operationally gauge-corrected (TRMM 3B42) and uncorrected (TMPA real time product, TRMM_RT) quantitative precipitation estimates (QPE) products was also made, resulting on TRMM 3B42 modestly having superior skill scores and the lowest false alarm ratios compared with the other non-corrected products.

\subsubsection{CHIRPS}

The CHIRPS quasi-global $\left(50^{\circ} \mathrm{S}-50^{\circ} \mathrm{N}\right)$ dataset was developed to support the United States Agency for International Development Famine Early Warning Systems Network (FEWS-NET) (Funk et al., 2015). CHIRPS uses the Tropical Rainfall Measuring Mission Multi-satellite Precipitation Analysis version 7 (TMPA 3B42 v7) to calibrate global cold cloud duration (CCD) rainfall estimates. The station data incorporation is done in two phases. The first one yields a 2-day latency preliminary rainfall product by merging sparse World Meteorological Organization's Global Telecommunication System (GTS) gauge data and data from stations in Mexico with CCD-derived rainfall estimates at every pentad. In the second phase, the best available monthly (and pentadal) station data are combined with monthly (and pentadal) high-resolution CCD-based rainfall estimates to produce the final product with a $\sim 3$-week latency. The final product yields into a high resolution $\left(0.05^{\circ}\right)$, daily, pentadal, and monthly precipitation dataset available at ftp://ftp.chg.ucsb.edu/pub/org/ chg/products/CHIRPS-2.0/

Perdigón-Morales et al. (2017) evaluated the performance of this product in estimating the duration and intensity of the MSD in Mexico for the 1981-2010 period. As a result, CHIRPS provided a more detailed spatial representation of the MSD than had been obtained before. Therefore, CHIRPS data, interpolated to the geographical points of the SMN climatological stations, is acceptable in reproducing the climatological values of the monthly precipitation accumulations in Mexico. Table II shows a summary of characteristics for each one of the products used in this study.

Table II. Main dataset specifications.

\begin{tabular}{lcccc}
\hline Dataset & GLDAS & ERA5 & TRMM 3B42 & CHIRPS \\
\hline Spatial resolution & $0.25^{\circ} \times 0.25^{\circ}$ & $0.25^{\circ} \times 0.25^{\circ}$ & $0.25^{\circ} \times 0.25^{\circ}$ & $0.05^{\circ} \times 0.05^{\circ}$ \\
Precipitation units & $\mathrm{kg} / \mathrm{m}^{2} / \mathrm{s}$ & $\mathrm{kg} / \mathrm{m}^{2} / \mathrm{s}$ & $\mathrm{mm} / \mathrm{h}$ & $\mathrm{mm}$ \\
Temporal resolution & 3 hours & Hourly & 3 hours & Daily \\
\hline
\end{tabular}




\subsection{Evaluation methodology}

Since in-situ precipitation observations are only available daily, the evaluation in this study is performed on a daily time scale. Therefore, the sub-daily products were aggregated in a daily time scale. Four main steps were followed to compare the reanalysis and satellite precipitation products against in-situ rain gauge measurements:

Step 1. All gridded datasets were re-gridded to a $1-\mathrm{km}^{2}$ resolution using bilinear interpolation through NCAR command language (NCL) scripts that utilize the Earth System Modeling Framework (ESMF) re-gridding functions. The $1-\mathrm{km}^{2}$ grid is the spatial grid used in the hydrological model domain. This resolution was chosen because it is the minimum resolution necessary to represent adequately the topographic features of the study region and is widely used in other hydrologic studies, for example in the operational U.S. National Water Model (https://water. noaa.gov/about/nwm).

Step 2. In-situ rainfall measurements are available at a daily time scale, reporting at 8:00 LT. Therefore, all other sub-daily products were accumulated from 9:00 LT on that day to 8:00 LT on the following day to calculate daily rainfall.

Step 3. Two main approaches were used to compare precipitation estimates against in-situ observations: (1) point to grid comparison of the in-situ observed rainfall against the precipitation estimates from the collocated $1-\mathrm{km}^{2}$ pixel; and (2) a comparison of the mean areal precipitation (MAP) values of the gridded precipitation against the MAP values of the in-situ observations over the watersheds. For the gridded products, MAP is the spatially averaged precipitation over each watershed numbered in Figure 1, considering the pixels within each of them. For the in-situ precipitation observation, MAP values are calculated using Thiessen polygons. This method is commonly used in hydrology to assign an influence area to each ground gauge location by bisecting lines connecting the gauges, thus forming polygons to estimate average precipitation in a basin (Raudkivi, 1979).

Step 4. Four different metrics were used to evaluate the agreement between estimated and observed precipitation values: Pearson correlation coefficient (Eq. 1), mean values for each station over all days, multiplicative bias (Eq. 2), and root mean square error (RMSE) (Eq. 3). To evaluate the performance of each dataset for events with different magnitudes these metrics were calculated for the following thresholds: $0-10,10-50,50-100$, and above $100 \mathrm{~mm}$, as well as for all the precipitation values (unconditional statistics). These thresholds were selected based on the potential damage degree that can be produced: minimum, low, high, and very high.

The Pearson correlation coefficient $\left(r_{x y}\right)$ is the ratio between the sample covariance $S_{x y}$ and the product of the standard deviations from the observed and estimated values, $S_{x}$ and $S_{y}$, respectively, for each station over all days (Eq. [1]), where the superscript $j$ indicates the $j^{\text {th }}$ station and $n$ is the total number of precipitation data pairs for that station.

$$
\begin{aligned}
& r_{x y}^{j}=\frac{S_{x y}^{j}}{S_{x}^{j} S_{y}^{j}} \\
& S_{x y}^{j}=\frac{\sum_{i=1}^{n}\left(x_{i}^{j}-\bar{x}^{j}\right)\left(y_{i}^{j}-\bar{y}^{j}\right)}{n-1}, S_{x}^{j}=\sqrt{\frac{\sum_{i=1}^{n}\left(x_{i}^{j}-\bar{x}^{\prime}\right)^{2}}{n-1}} \\
& S_{y}^{j}=\sqrt{\frac{\sum_{i=1}^{n}\left(y_{i}^{j}-\bar{y}^{\prime}\right)^{2}}{n-1}}
\end{aligned}
$$

The correlation coefficient allows to measure the association between two variables, in this case the daily observed and estimated precipitation. It can take a range of values from -1 to +1 , where \pm 1 indicates a perfect correlation between the two variables. A value greater than zero indicates a positive association, less than zero a negative association and equal to zero, no association.

The multiplicative bias (MultiBias) is the ratio between the mean of the precipitation estimate $\left(F_{l}^{j}\right)$ for each station over all days to the corresponding mean of the observed precipitation $\left(O_{i}^{j}\right)$. It is represented by Eq. (2), where the superscript $j$ indicates the $j^{\text {th }}$ station and $N$ the total number of days of precipitation. Therefore, a value higher than 1 means the model is overestimating the precipitation, while values bellow 1 indicate precipitation underestimation.

$$
\text { MultiBias }=\frac{\frac{1}{N} \sum_{i=1}^{N} F_{i}^{j}}{\frac{1}{N} \sum_{i=1}^{N} O_{i}^{j}}
$$

The root mean square error (RMSE) is the square root of the square differences between the estimated and observed precipitation for each station over all days. The perfect score is zero.

$R M S E=\sqrt{\frac{\sum_{i=1}^{N}\left(F_{i}^{j}-O_{i}^{j}\right)^{2}}{N}}$ 


\section{Results}

The comparison of different rainfall products versus the in-situ measurements are provided in this section. As mentioned in section 2.3, all products were re-gridded to $1-\mathrm{km}$ grids for the use in the hydrological model, and all the metrics are calculated based on the re-gridded data. Figure 2 shows the mean annual precipitation over the analysis period for each dataset in their native spatial resolution (Table II). There is a reasonable agreement between the spatial pattern of CHIRPS and ERA5. However, there is not much spatial variability in GLDAS and TRMM, and GLDAS seems pretty uniform in space. In terms of the overall precipitation intensity, CHIRPS, ERA5 and GLDAS are on the same order, while TRMM has significantly lower values compared to the other three products. The colored dots in Figure 2 show the in-situ mean annual precipitation intensity at the meteorological stations. Note from this plot that TRMM has significantly lower values in most of the domain compared to the mean annual observed rainfall over the study period. Also, GLDAS does not have the required spatial variability, and the estimated rainfall is almost uniform everywhere; therefore, the measured rainfall is overestimated at some locations while underestimated at others.

\subsection{Point to grid comparison}

Figure 3 shows a heat map of the estimated daily rainfall from CHIRPS, ERA5, GLDAS and TRMM 3B42 vs. the observed daily rainfall at 32 meteorological stations. Each point corresponds to the precipitation registered in one day during the analysis period for each station within the domain, therefore, all the

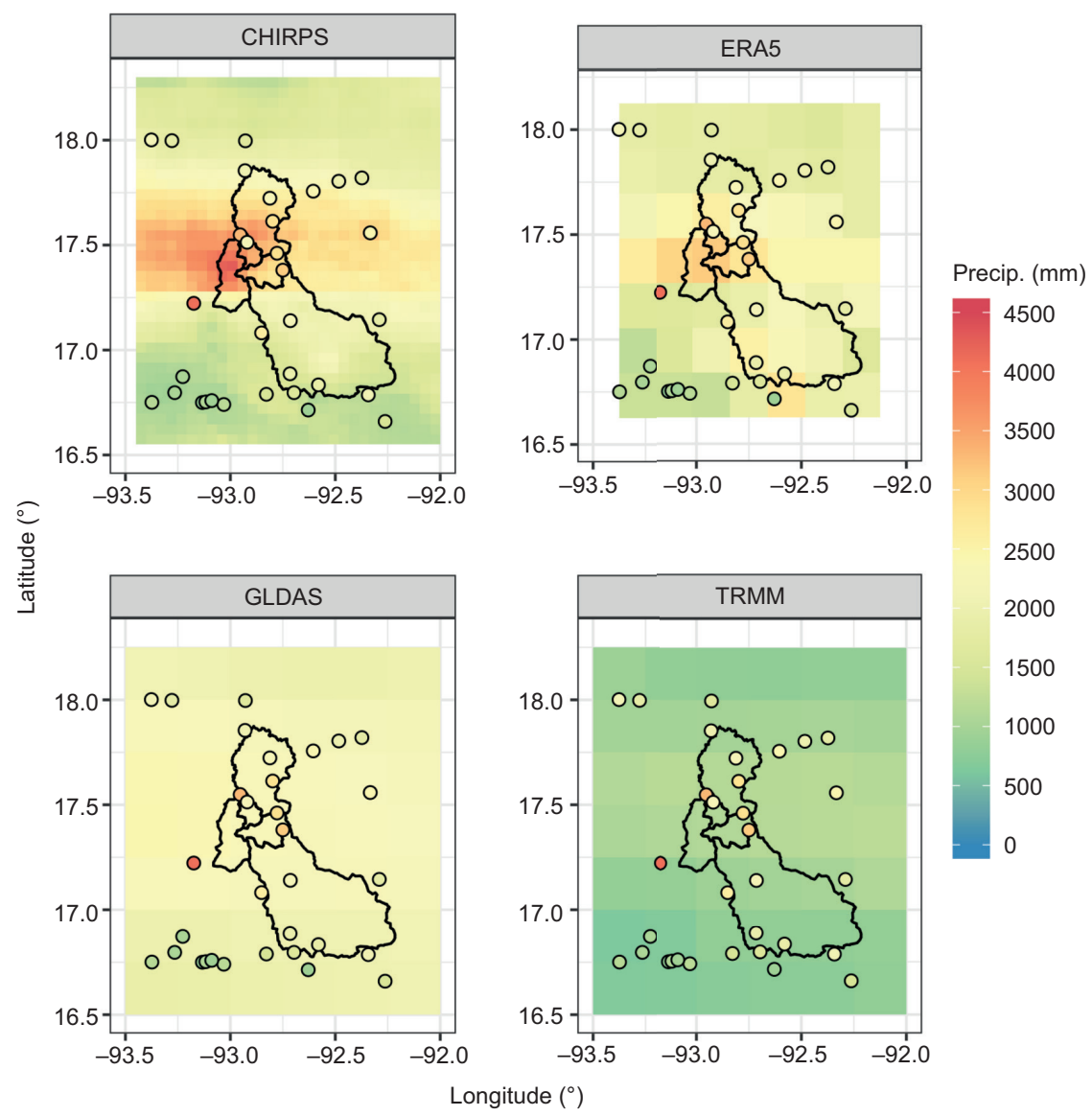

Fig. 2. Mean annual precipitation for each dataset over the study area during the analysis period on its native grid resolutions. 


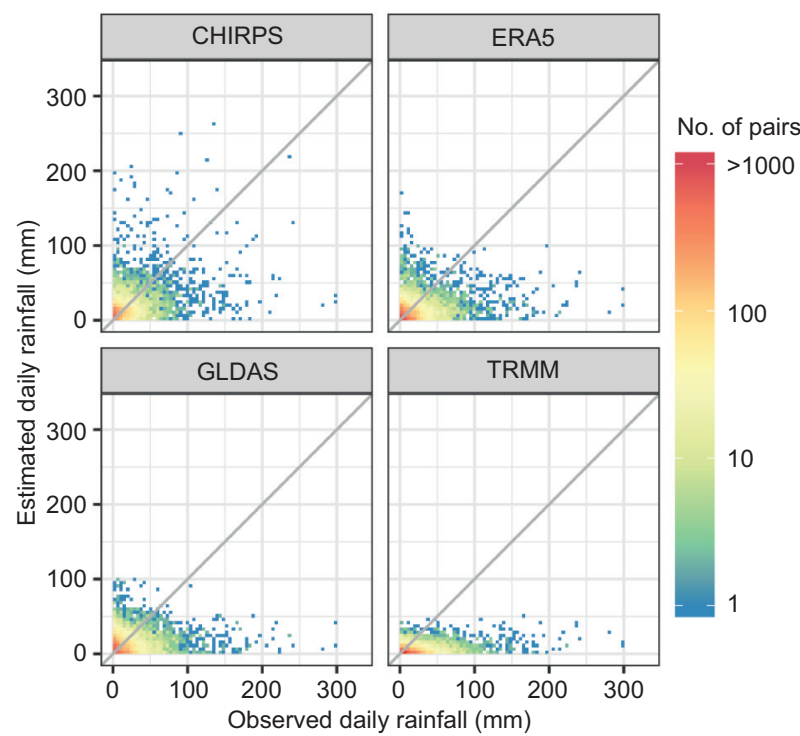

Fig. 3. Heat map of estimated precipitation for each dataset against the observed rainfall. Color represent the number of pairs in a given bin.

values registered for each station are plotted for each dataset, including days where the registered precipitation was zero. It also shows that TRMM 3B42 and GLDAS have a negative bias, which means that they tend to underestimate the precipitation values. ERA5 shows a slightly better performance. It does underestimate the intense precipitation events, but the degree of underestimation is lower than that of TRMM 3B42 and GLDAS. CHIRPS shows the best behavior of the compared datasets and less systematic underestimation. However, it has a large data scatter and a tendency to overestimate small rainfall events.

Figure 4 shows the mean daily precipitation estimates for each rainfall product over all the analysis period against the mean observed rainfall at the gauge location for each station. Points around the 1:1 line indicate agreement between the mean of the precipitation estimate at the gauge locations with observation. Again, CHIRPS estimates show the best behavior, followed by ERA5. In the case of GLDAS, it is producing the same amount of rainfall on most of the gauges, as expected given the uniformity of GLDAS that was shown in Figure 2 over the region of study. GLDAS overestimates for low rainfall amounts and underestimates for high mean rainfall values. The mean of the precipitation at all the gauges were underestimated by TRMM indicating that this product has high negative biases in the precipitation and will not be a very useful dataset when the total volume of the water on a watershed is of importance.

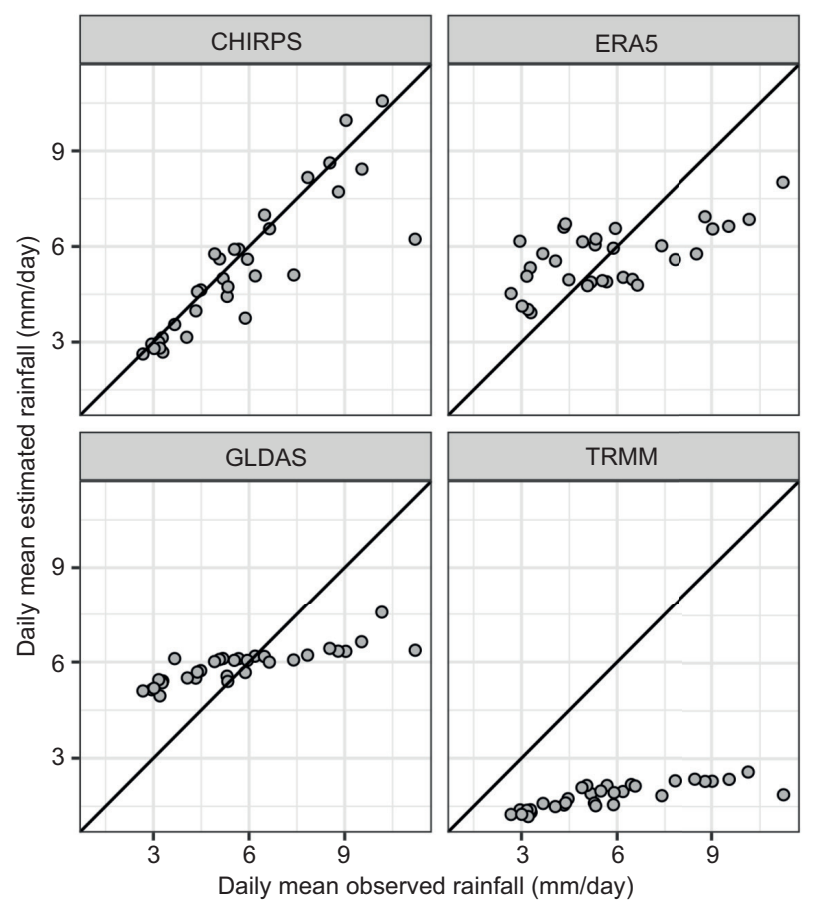

Fig. 4. Scatter plot of daily mean estimated and observed rainfall for each dataset.

The point to grid comparison was also evaluated through statistics summarized in box-plot diagrams. Figure 5 shows mean estimated precipitation at the station locations, Pearson correlation coefficient, RMSE and multiplicative bias calculated based on the estimated rainfall for each dataset against the observed rainfall for all stations within the study area.

The closest median of the mean precipitation is estimated by CHIRPS, followed by ERA5 and GLDAS, both overestimating its value, while TRMM 3B42 tends to underestimate it. CHIRPS has a more disperse distribution, positively skewed, that is the closest to the distribution in the observed values. On the other hand, even if it tends to slightly overestimate the median, ERA5 has less variability showing a tighter distribution and less skewed in comparison with CHIRPS and the observed values.

CHIRPS is the least biased dataset in terms of multiplicative bias, with a median close to 1 , which 

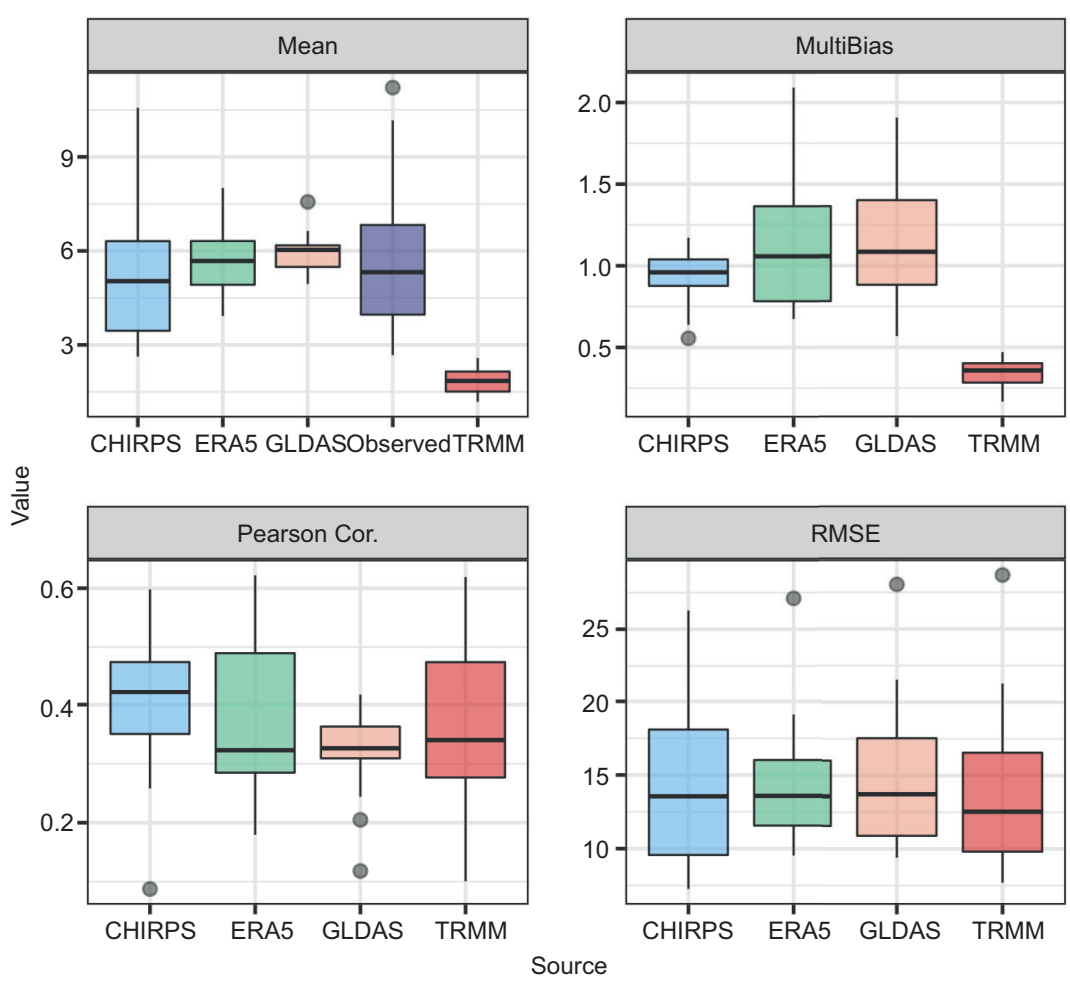

Fig. 5. Statistics over all the analysis period for point to grid comparison.

indicates that the mean of the observed and estimated precipitation are very close to each other, and it also shows a very tight distribution. On the other hand, close to $50 \%$ of the values in both ERA 5 and GLDAS datasets are above 1, indicating they tend to overestimate and underestimate precipitation in almost the same amount. According to the previous results, they tend to underestimate high precipitation values and overestimate the low ones. On the other hand, TRMM 3B42 consistently underestimates it in all cases.

CHIRPS has the highest median of the Pearson correlation coefficient showing a tight distribution of correlations. It is followed by ERA5 with around $12 \%$ of the correlation values above the ones obtained by CHIRPS and TRMM 3B42. GLDAS and TRMM 3B42 have a median value close to the one obtained by ERA5; however, GLDAS has a very tight distribution with correlation values not as high as the rest of the datasets and TRMM 3B42 has the highest dispersion in comparison to the rest of the datasets.

Finally, according to the RMSE the median value is almost the same for all the datasets; however,
ERA5 has the tighter distribution with the lowest RMSE values. This is followed by CHIRPS which has around $25 \%$ values lower than the ones obtained by ERA5 but with a more disperse distribution positively skewed. On the other hand, GLDAS and TRMM 3B42 have a disperse distribution in comparison to ERA5 with high RMSE values including the outliers.

Conditional statistics for precipitation in different threshold values are shown in Figure 6. Multiplicative bias is larger than 1 for precipitation events in the range of $0-10 \mathrm{~mm}$ for all the datasets except TRMM 3B42 and smaller than 1 for the rest of the precipitation ranges, which means that low precipitation values are overestimated by all the datasets except TRMM 3B42 and high precipitation values tend to be underestimated by all the datasets.

The correlation coefficient values diminish as the rainfall depth increases and turn to negative correlation at many stations for rainfall values greater than $100 \mathrm{~mm}$. Regarding the Pearson correlation coefficient, ERA5 has the highest value for events in the ranges of $0-10 \mathrm{~mm}$ and of 50-100 $\mathrm{mm}$, while 

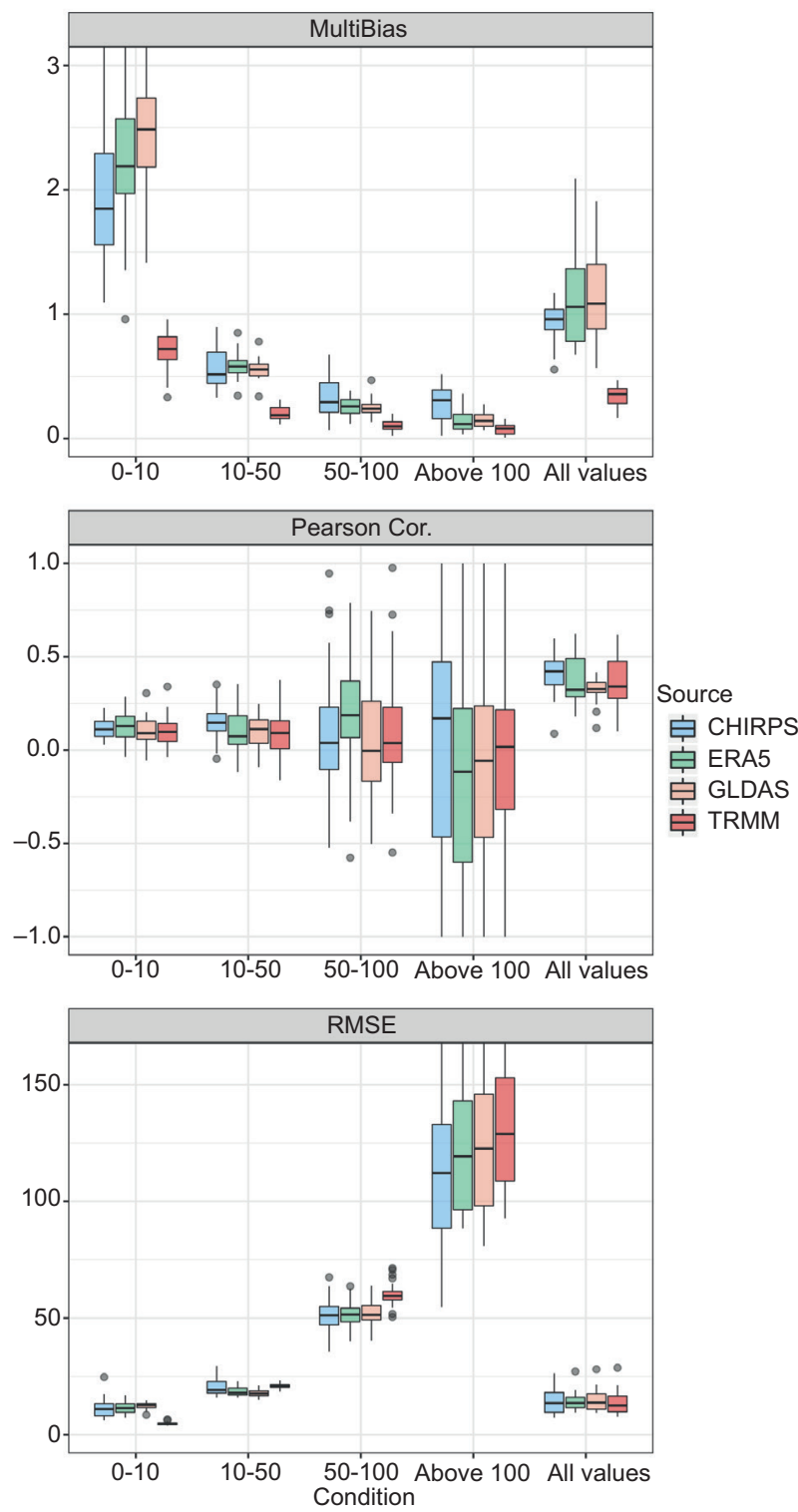

Fig. 6. Conditional multiplicative bias, Pearson correlation coefficient, RMSE and on point to grid comparison.

CHIRPS has higher correlations than ERA5 in ranges of $10-50 \mathrm{~mm}$, above $100 \mathrm{~mm}$, and for all the precipitation events. These two datasets have higher correlation values followed by GLDAS. All datasets show a broad distribution of correlation values for precipitation events above $100 \mathrm{~mm}$, highlighting the large variability on the estimates of high precipitation events.

Finally, the RMSE values show errors in all datasets are greater for larger precipitation values which is expected since RMSE is dependent on the precipitation values. TRMM $3 \mathrm{~B} 42$ has the smallest RMSE value for low precipitation events in a range of 0-10 mm, followed by CHIRPS, ERA5 and GLDAS. On the other hand, GLDAS has the lowest errors for events between 10-50 mm but it is closely followed by ERA5 and CHIRPS. CHIRPS has slightly lower errors on higher events in the ranges $50-100 \mathrm{~mm}$ and above $100 \mathrm{~mm}$.

\subsection{Mean areal precipitation}

Accuracy of the total rainfall over the watershed area is an important factor in hydrological modeling. If precipitation was misplaced in the point to grid analysis, then the errors would be larger and that is why some studies use a neighborhood approach when verifying the precipitation estimates and forecasts (Schwartz, 2016). We acknowledge that the spatial rainfall pattern will play an important role in the streamflow timing; however, the bias in the streamflow is more dependent on the accuracy of the mean areal precipitation over the watershed than on the spatial pattern. Therefore, we compared the estimated and observed mean areal precipitation over the four watersheds in the study area. The same metric as the point to grid comparison is used here. The distribution of the daily mean areal precipitation for each dataset and watershed is shown in Figure 7 through scatter plots, while the obtained metrics are summarized in Table III.

Results of Table III indicate that in basin number 1, the mean of the daily MAP obtained is better represented by GLDAS; however, ERA5 has the highest correlations. The rest of the datasets show very close correlation coefficients while TRMM 3B42 has the lowest RMSE. As it is shown in the scatter plots, CHIRPS is the dataset with the lowest dispersion; however, it tends to overestimate zones with low rainfall in high amounts. In contrast, ERA5 tends to do the opposite in a few zones with high rainfall. Based on the mean annual precipitation shown in Figure 2, rainfall in basin 1 had the lowest precipitation amounts and least variability in comparison with the rest of the basins; therefore, GLDAS and TRMM 3B42 show medium performances. Overall, ERA5 and GLDAS show the best performances.

On the other hand, ERA5 has the best performance for basins 2 and 3 according to the correlation, RMSE 

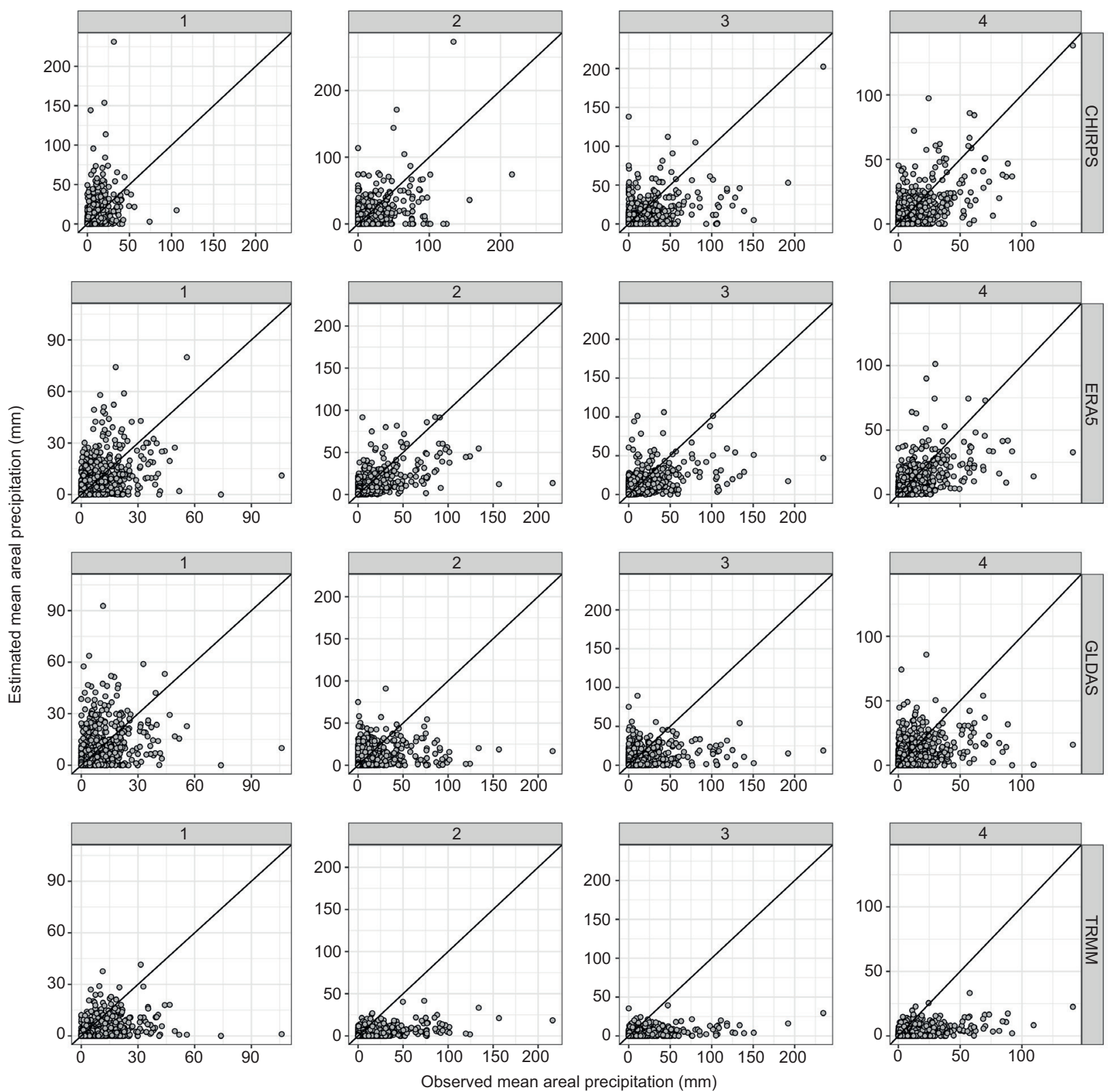

Fig. 7. Scatter plot of mean areal estimated and mean observed precipitation for each dataset. The number labels represent each basin in the study area.

and mean values, with the exception that mean values are better represented by CHIRPS over basin 2 . The last can be seen also in the scatter plots where ERA5 shows the more consistent distribution and less scattered.

It is CHIRPS in the case of basin 4 which has the best performance in comparison with the rest of the datasets based on the statistics and the scatter plots.
According to the analyses done, ERA5 and CHIRPS are superior in representing the spatial rainfall variability for basins 2 to 4 .

\subsection{Discussion}

The results presented indicate that the overall performance of the analyzed datasets is in the following decreasing order: CHIRPS, ERA5, GLDAS, and 
Table III. Mean areal precipitation statistics for each basin and dataset (the best metric value is indicated in gray).

\begin{tabular}{ccccccc}
\hline Basin & $\begin{array}{c}\text { Mean } \\
\text { observed }(\mathrm{mm})\end{array}$ & Source & $\begin{array}{c}\text { Mean model } \\
(\mathrm{mm})\end{array}$ & $\begin{array}{c}\text { Pearson } \\
\text { correlation }\end{array}$ & RMSE (mm) & MultiBias \\
\hline 1 & 5.922 & CHIRPS & 7.059 & 0.391 & 14.548 & 1.192 \\
& & ERA5 & 5.377 & 0.476 & 9.378 & 0.908 \\
& & GLDAS & 6.092 & 0.397 & 10.514 & 1.029 \\
& & TRMM & 2.201 & 0.396 & 9.255 & 0.373 \\
\hline \multirow{2}{*}{9.115} & CHIRPS & 7.993 & 0.511 & 18.374 & 0.877 \\
& & ERA5 & 7.459 & 0.633 & 15.268 & 0.818 \\
& & GLDAS & 6.241 & 0.333 & 19.014 & 0.685 \\
& & TRMM & 2.191 & 0.559 & 18.827 & 0.240 \\
\hline \multirow{2}{*}{9.383} & CHIRPS & 7.256 & 0.516 & 18.869 & 0.773 \\
& & ERA5 & 7.962 & 0.531 & 18.285 & 0.849 \\
& & GLDAS & 6.207 & 0.327 & 20.728 & 0.662 \\
& & TRMM & 2.026 & 0.462 & 21.237 & 0.216 \\
\hline 4 & & CHIRPS & 6.418 & 0.621 & 11.731 & 0.798 \\
& & ERA5 & 6.520 & 0.595 & 11.761 & 0.810 \\
& & GLDAS & 6.031 & 0.408 & 13.708 & 0.750 \\
& & TRMM & 1.890 & 0.527 & 14.252 & 0.236 \\
\hline
\end{tabular}

RMSE: root mean square error.

TRMM 3B42, with similar performances between ERA5 and CHIRPS.

The poor performance of TRMM 3B42 stands out compared to the rest of the products, especially compared to CHIRPS since both are satellite-based precipitation products. Bharti and Singh (2015) found that the TRMM precipitation product overestimates precipitation at elevations in ranges less than 3000 masl but severely underestimates it at higher elevations in the Himalaya region. Similar results were found by Ávila-Carrasco et al. (2018), who evaluated the TRMM 3B43V7 product on the Santiago River basin in Mexico for the 1998-2010 period through its comparison to a gridded precipitation database constructed from interpolation of 85 rain gauges using kriging. They found that the TRMM 3B43V7 product tends to underestimate precipitation in the coastal and mountainous regions and tends to overestimate it in the driest parts of the study area. Similarly, our results suggest that the poor performance of TRMM 3B42 could be due to the orographic complexities of the study area, since the upper part of the basin is predominantly mountainous while plains are more common on the lower part. Also, the quality and quantity of in-situ observations used for bias correction may have a role in the performance of TRMM 3B42.

Another source of bias originates from the type of typical clouds that vary in space. Precipitation produced by shallow orographic systems can be underestimated by microwave radiometer algorithms (Shige et al., 2013; Mayor et al., 2017). The better performance of CHIRPS against TRMM 3B42 could be the result of two main differences between the two products. First, CHIRPS is based on TRMM 3B42 to calibrate global CCD rainfall estimates considering information from multiple agencies including data from stations in Mexico, Central, and South America (see section 2.2.5). And second, despite having a coarser temporal resolution than the rest of the products, it has the highest spatial resolution, allowing for a better spatial representation of phenomena at higher scales.

ERA5 also shows a reasonable performance comparable to CHIRPS. ERA5 is a new product (2016) that replaces ERA-Interim and benefits from a decade of developments in model physics, core dynamics, and data assimilation techniques (4D-Var 
as mentioned in section 2.2.3), assimilating around 24 millions of observations per day including satellite-radiances and ground-based radar observations (Hersbach et al., 2018). The temporal resolution also plays an essential role in performance, as shown in Table III. ERA5's hourly temporal resolution is an advantage over the rest of the datasets, since it allows a much-refined view of the evolution of weather systems and could particularly play an important role during intense flash flooding events which last on the order of hours or less. GLDAS showed a poor performance compared to ERA5 and CHIRPS; an important characteristic that might play a role in the results is that it does not model atmospheric fields explicitly, hence it does not represent the physics behind precipitation processes, but instead relies on land surface models forced by observation-based meteorological fields using data assimilation techniques to incorporate observations of land surface states to curb unrealistic model states (Rodell et al., 2004). Therefore, its performance is related to the observations used for bias correction and could result in poor estimates in the case of low-quality observational data

The uneven gauge distribution might have also caused a possible distortion of the results due to a misrepresentation of the MAP on the true precipitation field.

\section{Conclusions}

The objective of this study was to evaluate reanalysis and satellite-based precipitation at a regional scale over the La Sierra river basins located in southern Mexico. The analyzed products were GLDAS, ERA5, TRMM 3B42, and CHIRPS over a 3-year period from 2008 to 2010, comparing in-situ observed rainfall vs. precipitation estimated by each product. The comparisons were done on point to grid comparison of the in-situ observed rainfall against the precipitation estimates from the collocated $1-\mathrm{km}$ pixel and a comparison of the MAP values of the gridded precipitation against the MAP values of the in-situ observations.

The relevant findings for the study area were:

- According to the point to grid comparison, CHIRPS showed the best performance among the four products in representing the mean daily values over the analysis period and the best non-conditional statistics, showing the highest correlation, lowest RMSE and multiplicative bias values, closely followed by ERA5.

- GLDAS and TRMM 3B42 tend to underestimate daily precipitation values.

- According to the conditioned statistics, all the datasets show a broad spectrum of correlation values for precipitation events above $100 \mathrm{~mm}$, highlighting the large variability in estimates of high precipitation events.

- All the products are highly biased on low precipitation events, which means that all the datasets tend to overestimate low precipitation events (except TRMM 3B42), and they tend to underestimate high precipitation events.

- ERA5 has the highest correlation values for events in the ranges of $0-10 \mathrm{~mm}$ and $50-100 \mathrm{~mm}$, while CHIRPS has higher correlations than ERA5 in ranges of 10-50 $\mathrm{mm}$, above $100 \mathrm{~mm}$, and for all the precipitation events without condition. These two datasets are followed by GLDAS.

- ERA5 and CHIRPS are the datasets with the best capability to represent the spatial rainfall variability according to the mean annual precipitation and mean areal precipitation analysis over the study area.

We conclude that CHIRPS is a convenient product if the application requires only precipitation data, whereas ERA5 is appropriate when other atmospheric variables are required, for instance if the dataset is used to force hydrological models.

It is important to highlight that the results are particular to the current analysis and study area, and considering the limited number of products explored, other datasets might show better results. Lastly, the methodology shown in this study could lay the foundation for an analysis of different atmospheric regimes in the future.

\section{Acknowledgments}

This study is part of the Ph.D. thesis of the first author developed at the Programa de Maestría y Doctorado en Ingeniería, Universidad Nacional Autónoma de México (UNAM), with the support of the Consejo 
Nacional de Ciencia y Tecnología (CONACYT). We would like to thank the NCAR's Real Applications Laboratory and Dr. David Gochis and his team for supporting and making this work possible through facilitating the computational resources and guidance during the analysis process, as well as Dr. Jorge Zavala-Hidalgo from the Centro de Ciencias de la Atmósfera and Dr. Ramón Domínguez-Mora from the Instituto de Ingeniería (both of UNAM) for their suggestions during the development of this work.

\section{References}

Adler RF, Negri AJ. 1988. A satellite infrared technique to estimate tropical convective and stratiform rainfall. Journal of Applied Meteorology 27: 30-51. https:// doi.org/10.1175/1520-0450(1988)027<0030:ASITTE $>2.0 . C O ; 2$

Adler RF, Huffman GJ, Chang A, Ferraro R, Xie P, Janowiak J, Rudolf B, Schneider U, Curtis S, Bolvin D, Gruber A, Susskind J, Arkin P, Nelkin E. 2003. The version-2 Global Precipitation Climatology Project (GPCP) monthly precipitation analysis (1979-present). Journal of Hydrometeorology 4: 1147-1166. https:// doi.org/10.1175/1525-7541(2003)004<1147:TVGP$\mathrm{CP}>2.0 . \mathrm{CO} ; 2$

Albuquerque de Almeida V, Marton E, Nunes AMB. 2018. Assessing the ability of three global reanalysis products to reproduce South American monsoon precipitation. Atmósfera 31: 1-10. https://doi.org/10.20937/ ATM.2018.31.01.01

Andersson A, Fenning K, Klepp C, Bakan S, Graß1 H, Schulz J. 2010. The Hamburg Ocean Atmosphere Parameters and Fluxes from Satellite data - HOAPS-3. Earth System Science Data 2: 215-234. https://doi. org/10.5194/essd-2-215-2010

Arkin PA, Joyce R, Janowiak JE. 1994. The estimation of global monthly mean rainfall using infrared satellite data: The GOES Precipitation Index (GPI). Remote Sensing Reviews 11: 107-124.

Arreguín-Cortés FI, Rubio-Gutiérrez H, Domínguez-Mora R, Luna-Cruz F. 2014. Análisis de las inundaciones en la planicie Tabasqueña en el periodo 1995-2010. Tecnología y Ciencias del Agua 5: 5-32.

Aurea de J, Breña-Naranjo JA, Pedrozo-Acuña A, Alcocer YVH. 2016. The use of TRMM 3B42 product for drought monitoring in Mexico. Water 8: 325. https:// doi.org/10.3390/w8080325
Ávila-Carrasco JR, Júnez-Ferreira HE, Gowda PH, Steiner JL, Moriasi DN, Starks PJ, González J, Villalobos AA, Bautista-Capetillo C. 2018. Evaluation of satellite-derived rainfall data for multiple physio-climatic regions in the Santiago River basin, Mexico. Journal of the American Water Resources Association 54: 1068-1086. https://doi.org/10.1111/1752-1688.12672.

Bharti VI, Singh C. 2015. Evaluation of error in TRMM 3B42V7 precipitation estimates over the Himalayan region. Journal of Geophysical Research: Atmospheres 12: 458-473. https://doi.org/10.1002/2015JD023779

Borga M. 2002. Accuracy of radar rainfall estimates for streamflow simulation. Journal of Hydrology 267: 2639. https://doi.org/10.1016/S0022-1694(02)00137-3

Bruster-Flores J, Ortiz-Gómez R, Ferriño-Fierro AL, Guerra-Cobián VH, Burgos-Flore D, Lizárraga-Mendiola LG. 2019. Evaluation of precipitation estimates CMORPH-CRT on regions of Mexico with different climates. Water 11: 1722. https://doi.org/10.3390/ w11081722

Ciach GJ. 2003. Local random errors in tipping-bucket rain gauge measurements. Journal of Atmospheric \& Oceanic Technology 20: 752-759. https://doi. org/10.1175/1520-0426(2003)20<752:LREITB $>2.0$. $\mathrm{CO} ; 2$

CONAGUA. 2013. Programa Nacional Contra Contingencias Hidráulicas RHA XI Frontera Sur. Comisión Nacional del Agua, México.

CONAGUA. 2015. Proyecto ejecutivo para la reconstrucción de la margen izquierda, del río La Sierra, a la altura Pueblo Nuevo de Las Raíces, Municipio de Centro, estado de Tabasco. Comisión Nacional del Agua, México.

Coning E. 2013. Optimizing satellite-based precipitation estimation for nowcasting of rainfall and flash flood events over the South African domain. Remote Sensing 5: 5702-5724. https://doi.org/10.3390/rs5115702

Dai Y, Zeng X, Dickinson RE, Baker I, Bonan GB, Bosilovich MG, Denning AS, Dirmeyer PA, Houser PR, Niu G, Oleson KW, Schlosser CA, Yang ZL. 2003. The Common Land Model. Bulletin of the American Meteorological Society 84: 1013-1023. https://doi. org/10.1175/BAMS-84-8-1013

Ek MB, Mitchell KE, Lin Y, Rogers E, Grunmann P, Koren V, Gayno G, Tarpley JD. 2003. Implementation of Noah land surface model advances in the National Centers for Environmental Prediction operational mesoscale Eta model. Journal of Geophysical Research 108: 8851. https://doi.org/10.1029/2002JD003296 
Funk C, Peterson P, Landsfeld M, Pedreros D, Verdin J, Shukla S, Husak G, Rowland J, Harrison L, Hoell A, Michaelsen J. 2015. The climate hazards infrared precipitation with stations - a new environmental record for monitoring extremes. Scientific Data 2: 150066 https://doi.org/10.1038/sdata.2015.66

Ghodichore N, Vinnarasi R, Dhanya CT, Baidya Roy S. 2018. Reliability of reanalyses products in simulating precipitation and temperature characteristics over India. Journal of Earth System Science 127: 115. https:// doi.org/10.1007/s12040-018-1024-2

Gochis DJ, Nesbitt SW, Yu W, Williams SF. 2009. Comparison of gauge-corrected versus non-gauge corrected satellite-based quantitative precipitation estimates during the 2004 NAME enhanced observing period. Atmósfera 22: 69-98.

Habib E, Krajewski WF, Kruger A. 2001. Sampling errors of tipping-bucket rain gauge measurements. Journal of Hydrologic Engineering 6: 159-166.

Hersbach H, Rosnay P, Bell B, Schepers D, Simmons A, Soci C, Abdalla S, Alonso BM, Balsamo G, Bechtold P, Berrisford P, Bidlot J, Boisséson E, Bonavita M, Browne P, Buizza R, Dahlgren P, Dee D, Dragani R, Diamantakis M, Flemming J, Forbes R, Geer A, Haiden T, Hólm E, Haimberger L, Hogan R, Horányi A, Janisková M, Laloyaux P, Lopez P, Muñoz-Sabater J, Peubey C, Radu R, Richardson D, Thépaut JN, Vitart F, Yang X, Zsótér E, Zuo H. 2018. Operational global reanalysis: Progress, future directions and synergies with NWP. ECMWF ERA Report Series 27. https:// doi.org/10.21957/tkic6g3wm

Hou AY, Kakar RK, Neeck S, Azarbarzin AA, Kummerow CD, Kojima M, Oki R, Namakura K, Iguchi T. 2014. The global precipitation measurement mission. Bulletin of the American Meteorological Society 95: 701722. https://doi.org/10.1175/BAMS-D-13-00164.1

Hsu KL, Gao XG, Sorooshian S, Gupta HV. 1997. Precipitation estimation from remotely sensed information using artificial neural networks. Journal of Applied Meteorology 36: 1176-1190. https:// doi.org/10.1175/1520-0450(1997)036<1176:PEFRSI $>2.0 . \mathrm{CO} ; 2$

Huffman GJ, Adler RF, Bolvin DT, Gu G, Nelkin EJ., Bowman KP, Hong Y, Stocker EF, Wolff DB. 2007. The TRMM Multisatellite Precipitation Analysis (TMPA): Quasi-global, multiyear, combined-sensor precipitation estimates at fine scales. Journal of Hydrometeorology 8: 38-55. https://doi.org/10.1175/JHM560.1
Joyce RJ, Janowiak JE, Arkin PA, Xie P. 2004. CMORPH: A method that produces global precipitation estimates from passive microwave and infrared data at high spatial and temporal resolution. Journal of Hydrometeorology 5: 487-503. https://doi. org/10.1175/1525-7541(2004)005<0487:CAMTP$\mathrm{G}>2.0 . \mathrm{CO} ; 2$

Koster RD, Suárez MJ. 1996. Energy and water balance calculations in the Mosaic LSM, technical report series on global modeling and data assimilation. Goddard Space Flight Center, Greenbelt, Maryland, USA.

Kuligowsky RJ. 2002. A self-calibrating real-time GOES rainfall algorithm for short-term rainfall estimates. Journal of Hydrometeorology 3: 112-130. https://doi.org/10 $.1175 / 1525-7541(2002) 003<0112$ :ASCRTG $>2.0 . C O ; 2$ Larson LW, Peck EL. 1974. Accuracy of precipitation measurements for hydrological modeling. Water Resources Research 10: 857-863. https://doi.org/10.1029/ WR010i004p00857

Liang X, Lettenmaier DP, Wood EF, Burges SJ. 1994. A simple hydrologically based model of land surface water and energy fluxes for general circulation models. Journal of Geophysical Research: Atmospheres 99: 14415-14428. https://doi.org/10.1029/94JD00483

Ly S, Charles C, Degré A. 2013. Different methods for spatial interpolation of rainfall data for operational hydrology and hydrological modeling at watershed scale. A review. Biotechnology, Agronomy, Society and Environment 17: 392-406.

MacRitchie K. 2017. README document for the Tropical Rainfall Measurement Mission (TRMM) Version 7. National Aeronautics and Space Administration Goddard Earth Science Data Information and Services Center (GES DISC).

Mayor YG, Tereshchenko I, Fonseca-Hernández M, Pantoja DA, Montes JM. 2017. Evaluation of error in IMERG precipitation estimates under different topographic conditions and temporal scales over Mexico. Remote Sensing 9: 503. https://doi.org/10.3390/rs9050503

Mendoza IU. 2019. Desempeño del algoritmo RRQPE del satélite GOES 16 para la estimación de lluvia en el estado de Nayarit tras el paso del huracán Willa. Ingeniería, Revista Académica de la Facultad de Ingeniería, Universidad Autónoma de Yucatán 23: 37-51.

Mitchell KE, Lohmann D, Houser PR, Wood EF, Schaake JC, Robock A, Cosgrove BA, Sheffield J, Duan Q, Luo L, Higgins RW, Pinker RT, Tarpley JD, Lettenmaier DP, Marshall CH, Entin JK, Pan M, 
Shi W, Koren V, Meng J, Ramsay BH, Bailey AA. 2004. The multi-institution North American Land Data Assimilation System (NLDAS): Utilizing multiple GCIP products and partners in a continental distributed hydrological modeling system. Journal of Geophysical Research 109: D07S90. https://doi. org/10.1029/2003JD003823

Nanding N, Rico-Ramírez MA, Han D. 2015. Comparison of different radar-raingauge rainfall merging techniques. Journal of Hydroinformatics 17: 422-445. https://doi.org/10.2166/hydro.2015.001

Nkiaka E, Nawaz NR, Lovett JC. 2017. Evaluating global reanalysis precipitation datasets with rain gauge measurements in the Sudano-Sahel region: Case study of the Logone catchment, Lake Chad Basin. Meteorological Applications 24: 9-18. https://doi.org/10.1002/ met. 1600

Paredes-Trejo FJ, Alves-Barbosa H, Peñaloza-Murillo MA, Moreno MA, Farías A. 2016. Intercomparison of improved satellite rainfall estimation with CHIRPS gridded product and rain gauge data over Venezuela. Atmósfera 29: 323-342. https://doi.org/10.20937/ ATM.2016.29.04.04

Parker WS. 2016. Reanalysis and observations. What's the difference? Bulletin of the American Meteorological Society 97: 1565-1572. https://doi.org/10.1175/ BAMS-D-14-00226.1

Perdigón-Morales J, Romero-Centeno R, Ordoñez PP, Barret SB. 2017. The midsummer drought in Mexico: Perspectives on duration and intensity from the CHIRPS precipitation database. International Journal of Climatology 38: 2174-2186. https://doi.org/10.1002/ joc. 5322

Raudkivi AJ. 1979. Hydrology: An advanced introduction to hydrological processes and modelling. Pergamon Press, Oxford, 479 pp.

Real-Rangel R, Pedrozo-Acuña A, Breña-Naranjo JA, Alcocer-Yamanaka VH. 2017. Evaluation of the hydroclimatological variables derived from GLDAS-1, GLDAS-2 and MERRA-2 in Mexico. In: E-proceedings of the 37th IAHR World Congress. August 13-18. Kuala Lumpur, Malaysia.

Rico-Ramírez M, Liguori S, Schellart A. 2015. Quantifying radar-rainfall uncertainties in urban drainage flow modelling. Journal of Hydrology 528: 17-28. https:// doi.org/10.1016/j.jhydrol.2015.05.057

Rienecker MM, Suárez MJ, Gelaro R, Todling R, Bacmeister JT, Liu E, Bosilovich MG, Schubert SD, Takacs
L, Kim GK, Bloom S, Chen J, Collins D, Conaty A, Da Silva A, Gu W, Joiner J, Koster RD, Lucchesi R, Molod A, Owens T, Pawson S, Pegion PJ, Redder CR, Reichle RH, Robertson FR, Ruddick AG, Sienkiewicz M, Woollen J. 2011. MERRA: NASA's modern-era retrospective analysis for research and applications. Journal of Climate 24: 3624-3648. https://doi.org/10.1175/ JCLI-D-11-00015.1

Rodell M, Houser PR, Jambor U, Gottschalck J, Mitchell K, Meng CJ, Arsenault K, Cosgrove B, Radakovich J, Bosilovich M, Entin JK, Walker JP, Lohmann D, Toll D. 2004. The Global Land Data Assimilation System. Bulletin of the American Meteorological Society 85: 381-394. https://doi. org/10.1175/BAMS-85-3-381

Sánchez-Sesma J, Sosa-Chiñas MA. 2007. EPPePMex, An operational real-time rainfall estimation for Mexico, based on GOES-IR imagery. 2nd Workshop of the International Precipitation Working Group. American Geophysical Union, spring meeting.

Schwartz CS. 2016. Improving large-domain convection-allowing forecasts with high-resolution analyses and ensemble data assimilation. American Meteorological Society 144: 1777-1802. https://doi.org/10.1175/ MWR-D-15-0286.1

Shige S, Kida S, Ashiwake H, Kubota T, Aonashi K. 2013. Improvement of TMI rain retrievals in mountainous areas. Journal of Applied Meteorlogy and Climatology 52: 242-254. https://doi.org/10.1175/ JAMC-D-12-074.1

Upton G, Rahimi A. 2003. On-line detection of errors in tipping-bucket rain gauges. Journal of Hydrology 278: 197-212. https://doi.org/10.1016/S00221694(03)00142-2

Villarini G, Krajewski WF. 2010. Review of the different sources of uncertainty in single polarization radar-based estimates of rainfall. Surveys in Geophysics 31: 107-129. https://doi.org/10.1007/s10712009-9079-x

Wang G, Zhang X, Zhang S. 2019. Performance of three reanalysis precipitation datasets over the Qinling-Daba Mountains, eastern fringe of Tibetan Plateau, China. Advances in Meteorology 2019: 7698171. https://doi. org/10.1155/2019/7698171

Xia Y, Mitchell K, Ek M, Sheffield J, Cosgrove B, Wood E, Luo L, Alonge C, Wei H, Meng J, Livneh B, Lettenmaier D, Koren V, Duan Q, Mo K, Fan Y, and Mocko D. 2012. Continental-scale water and energy flux 
analysis and validation for the North American Land Data Assimilation System project phase 2 (NLDAS-2): 1. Intercomparison and application of model products. Journal of Geophysical Research 117: D03110. https:// doi.org/10.1029/2011JD016048
Yucel I, Kuligowski RJ and Gochis D. 2009. Evaluation of the Hydro-Estimator satellite rainfall algorithm and its utility in hydrological prediction in a mountainous region. New Approaches to Hydrological Prediction in Data-sparse Regions. IAHS Publ. 333: 259-266. 